\title{
Growth of Strontium Chromium Magnesium Hydrogen Phosphate (SrCrMHP) Crystal in Silica Gel Medium at Different Growth Environments and Nucleation Reduction Strategy
}

\author{
G. Kanchana ${ }^{1}$, P. Suresh ${ }^{2}$, P. Sundaramoorthi ${ }^{2}$, S. Kalainathan ${ }^{3}$, G.P. Jeyanthi ${ }^{1}$ \\ ${ }^{1}$ Department of Bio-chemistry, Avinashilingam Deemed University, Coimbatore, \\ TamilNadu, India. \\ ${ }^{2}$ Department of Physics, A.A.Govt. Arts College, Namakkal - India-637001. \\ (sundara78@rediffmail.com) \\ ${ }^{3}$ Department of Physics, SSH, VIT University, Vellore - India
}

\begin{abstract}
Kidney stone consists of various organic, inorganic and semi organic compounds. Mineral oxalate monohydrate and di-hydrate are the main inorganic constituents of kidney stones. However, mechanisms leading to the formation of mineral oxalate kidney stones are not clearly understood. In this field of study, there are several hypotheses including nucleation, crystal growth and/or aggregation of formation of AOMH (Ammonium oxalate monohydrate) and AODH (Ammonium oxalate di-hydrate) crystals. The effect of some urinary species such as ammonium oxalate, calcium citrate, proteins and trace elements were reported by the author. The kidney stone constituents are grown in silica gel medium (SMS) which provides the necessary growth simulation (in-vivo). In the artificial urinary stone growth process, identification of growth parameters within the different chemical environment was carried out and reported for the urinary crystals such as CHP, SHP, BHP and MHP. In the present study, SrCrMHP (Strontium chromium magnesium hydrogen phosphate) crystals are grown in three different growth faces to attain the total nucleation reduction. Extension of this research, many characterization studies have been carried out and the results are reported.
\end{abstract}

Key words: $C H P, M H P, A M H P, S H P, S r C r M H P$, trace element, major minerals, minor minerals. 


\section{INTRODUCTION}

SHP (Strontium hydrogen phosphate), CHP (Calcium hydrogen phosphate) and BHP (Barium hydrogen phosphate) were grown in silica gel medium at room temperature. The next approach is to grow mixed crystal in silica gel medium at different environments, which contains one major element (Phosphate), two minor or trace elements (Strontium, Chromium) and one inhibitor (Magnesium). SrCrMHP is a mixed crystal, which typically represent the biological crystals formed in the human urinary tracts called renal stones. One can obtain the periodic precipitation of Liesegang rings of biological crystal named as Brushite, Struvite, HAP, BMHP and SMHP [1-9].

\section{EXPERIMENTAL PROCEDURES}

The dissociation of orthophosphoric acid system can be represented by three dissociation equilibrium and the presence of various ions at various $\mathrm{pH}$ values is studied. Based on these results, gel medium of $\mathrm{pH}$ in the range from 6 to 10 has been used in which the $\mathrm{HPO}_{4}{ }^{2-}$ ions dominates or alone exist. This decreases the possibility of SrCrMP crystals occurring during the SrCrMHP growth. The crystallization apparatus employed were glass test tubes of $25 \mathrm{~mm}$ diameter and $150 \mathrm{~mm}$ length for single diffusion process (SDP) and thick walled glass $U$ tubes of $30 \mathrm{~mm}$ diameter and $180 \mathrm{~mm}$ length for double diffusion process (DDP). The chemicals used were EXCELAR-Qualigens (E-Q) AR grade $\mathrm{CrCl}_{2}, \mathrm{SrCl}_{2}, \mathrm{Mg}\left(\mathrm{NO}_{3}\right)_{2} .2 \mathrm{H}_{2} \mathrm{O}(\mathrm{MW}-258.41)$ and orthophosphoric acid (Sp.gr.1.75). The SMS gel or water glass was prepared as per the literature. One of the reactants orthophosphoric acid was mixed with silica gel at desired gel density and elevated temperatures. After the gel set, the supernatant mixture (Chromium chloride +Strontium chloride + Magnesium nitrate) at a required mole solutions was slowly added along the walls of the growth columns (test tubes, U-tubes) over the set gels and tightly closed to prevent evaporation. Then the growth systems were allowed to react within the gel medium and the following chemical reaction takes place [10-14].

$\left(\mathrm{CrCl}_{2}+\mathrm{Mg}\left(\mathrm{NO}_{3}\right)_{2} \cdot 2 \mathrm{H}_{2} \mathrm{O}\right)+\mathrm{SrCl}_{2}+\mathrm{H}_{3} \mathrm{PO}_{4} \rightarrow \mathrm{SrCrMgHPO}_{4}+$ Waste.

Table-1 and Table-2 represent the growth parameters of SrCrMHP crystal and the bold letters represent the optimum growth parameters in SDP and DDP growth processes. The growth column of different growth environments are shown in Fig 1-6. 
TABLE-1.

Growth parameters of SrCrMHP crystal (SDP)

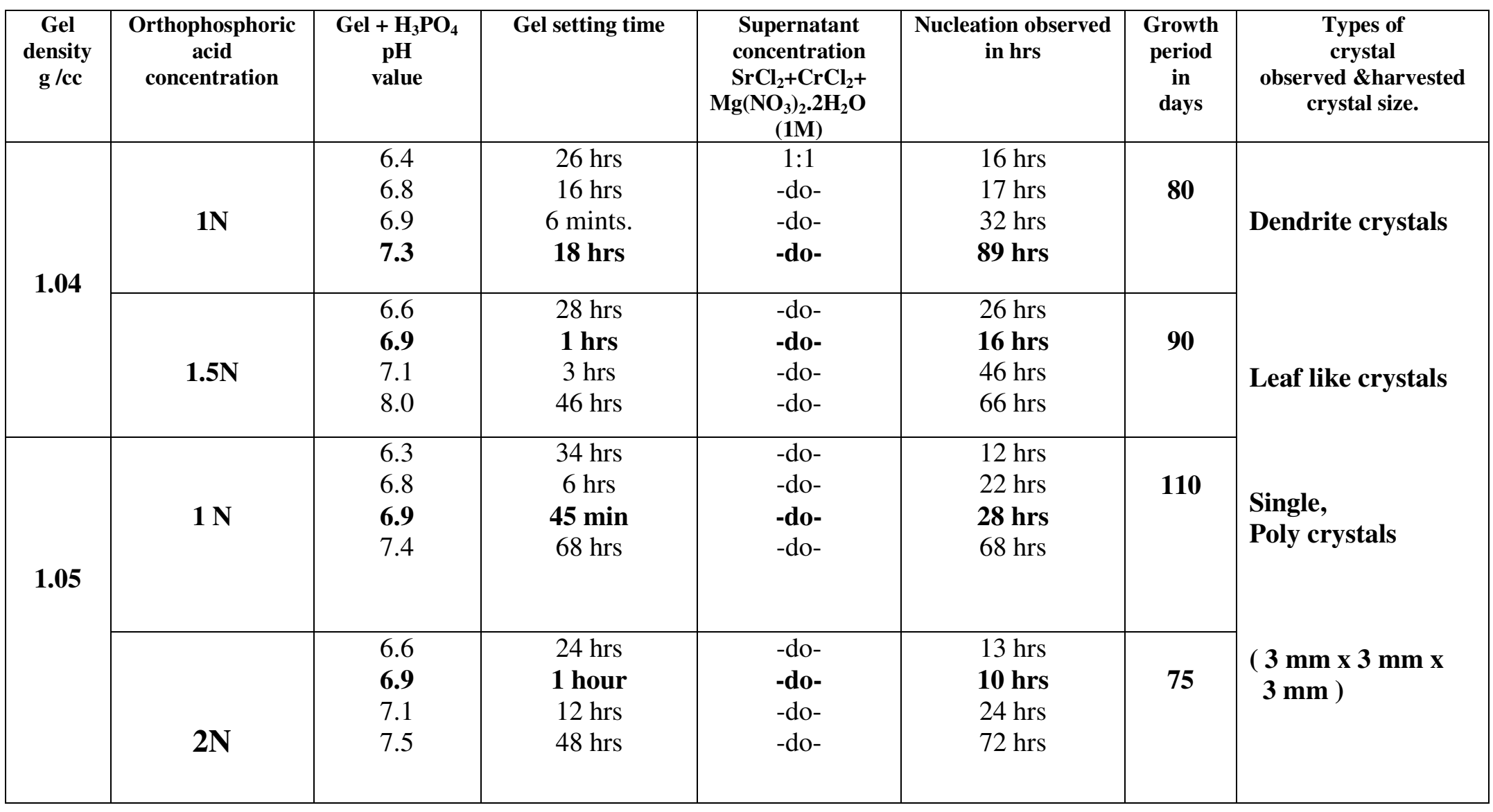


TABLE-2.

Growth parameters of SrCrMHP crystal (DDP)

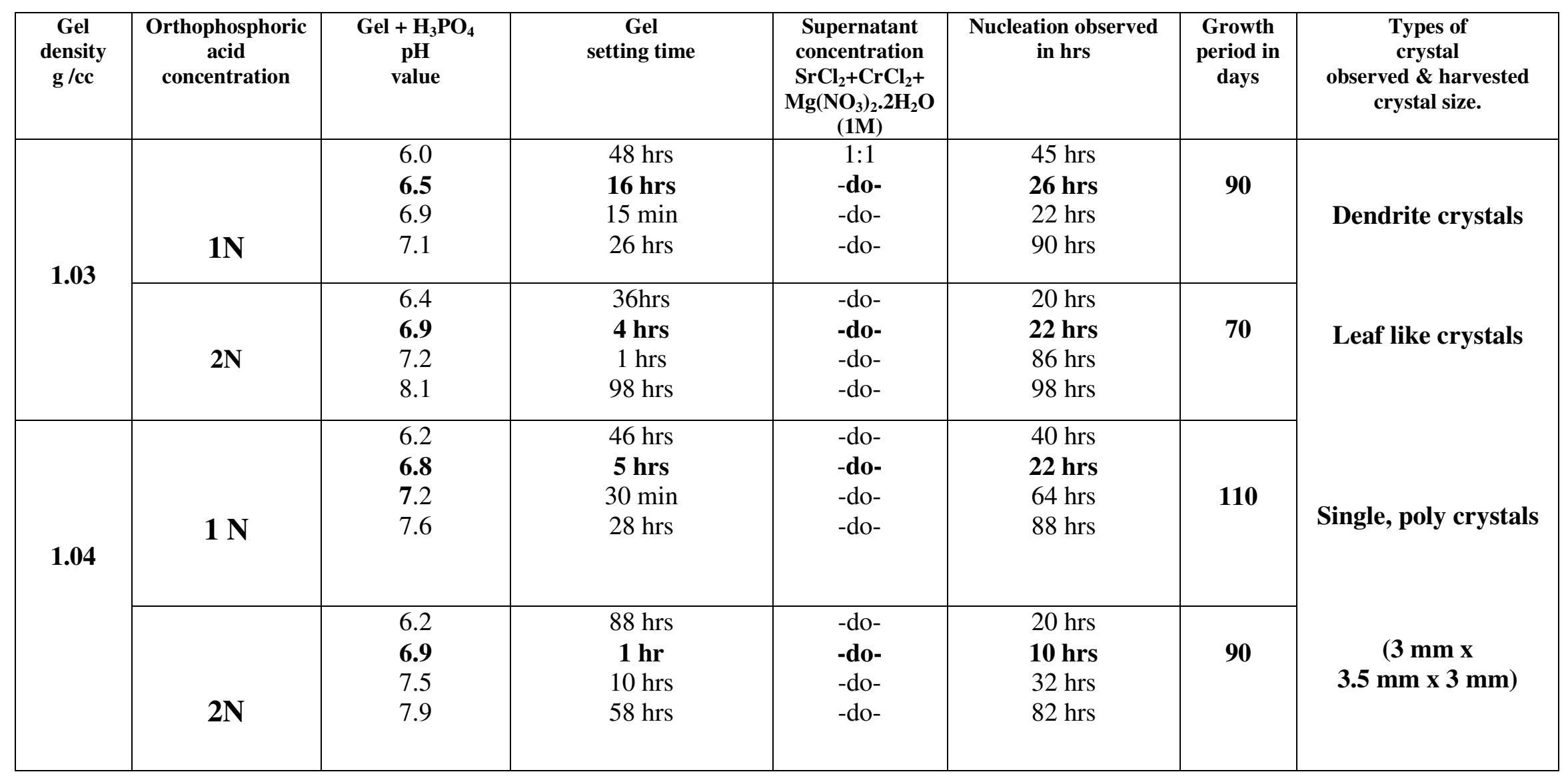




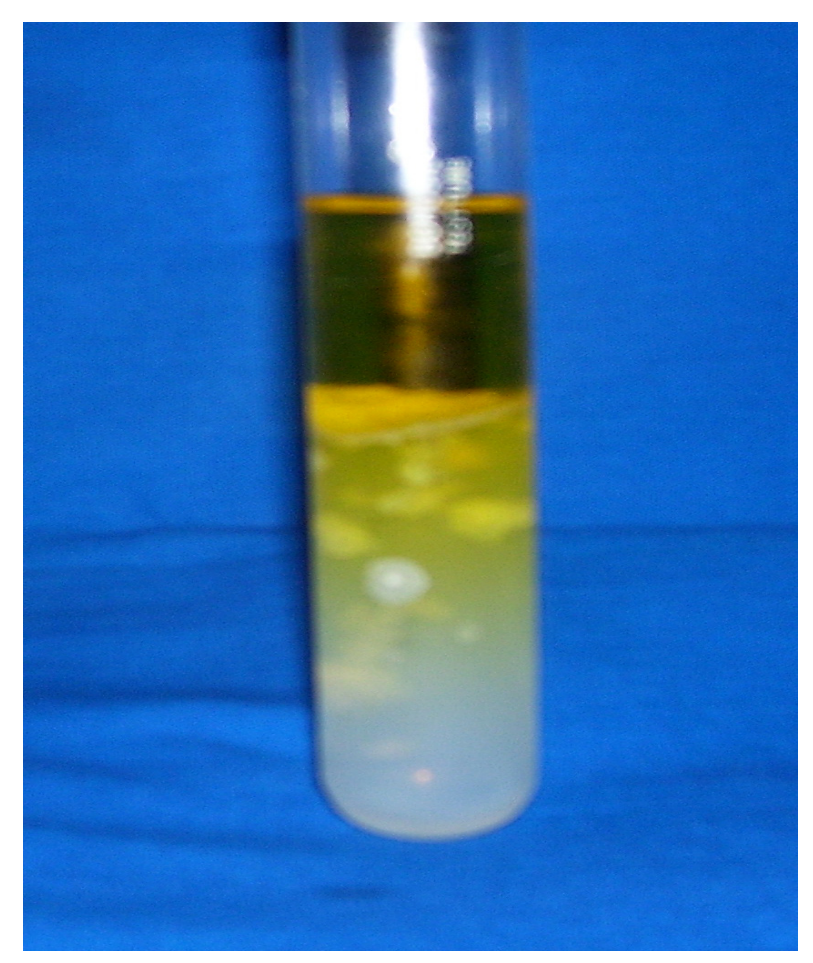

Fig-1. Growth of SrCrMHP crystal within laboratory environment (SDP).

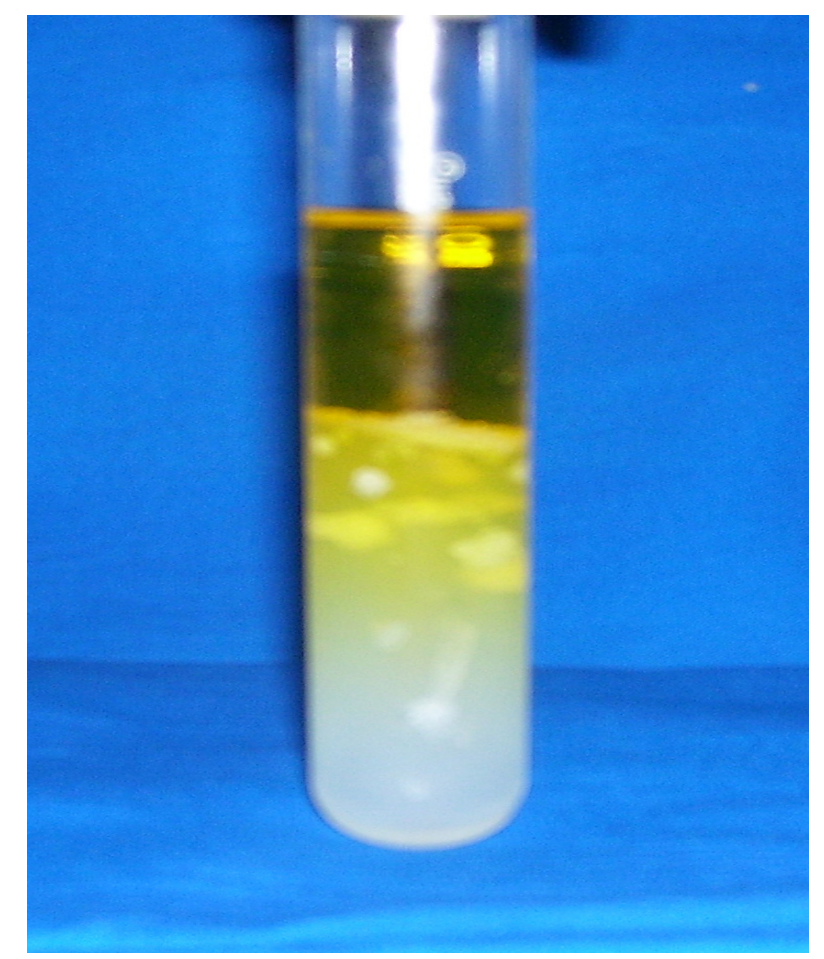

Fig -2. Growth of SrCrMHP crystal within laboratory environment (SDP). 


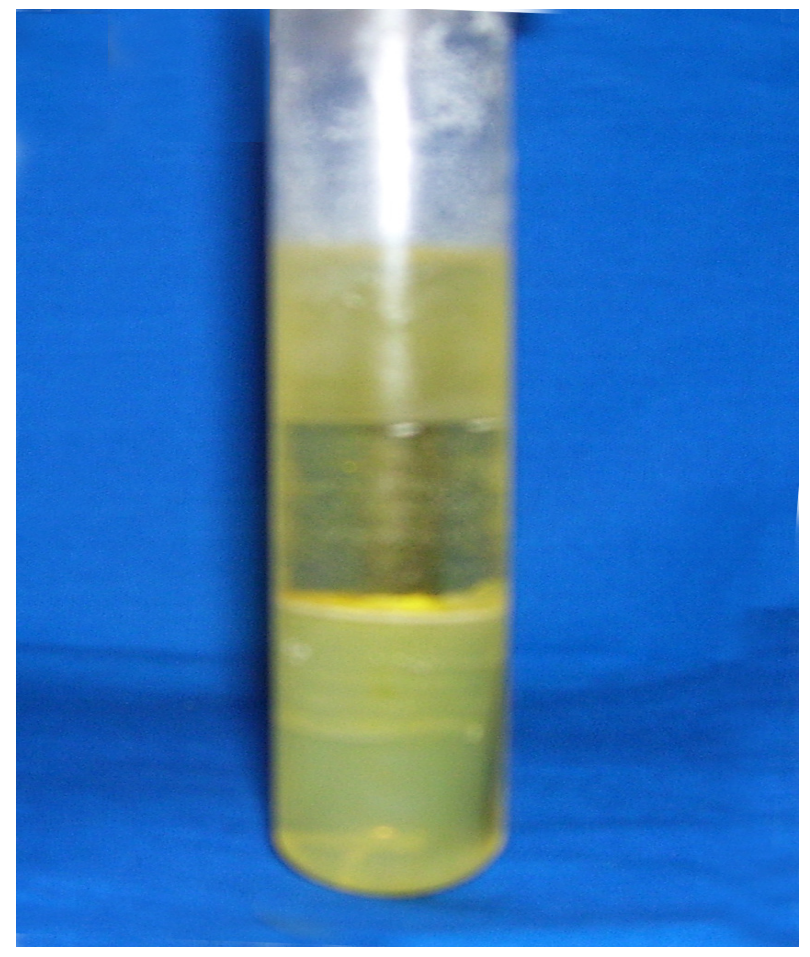

Fig-3. Growth of SrCrMHP crystal within sunlight exposed medium (SDP).

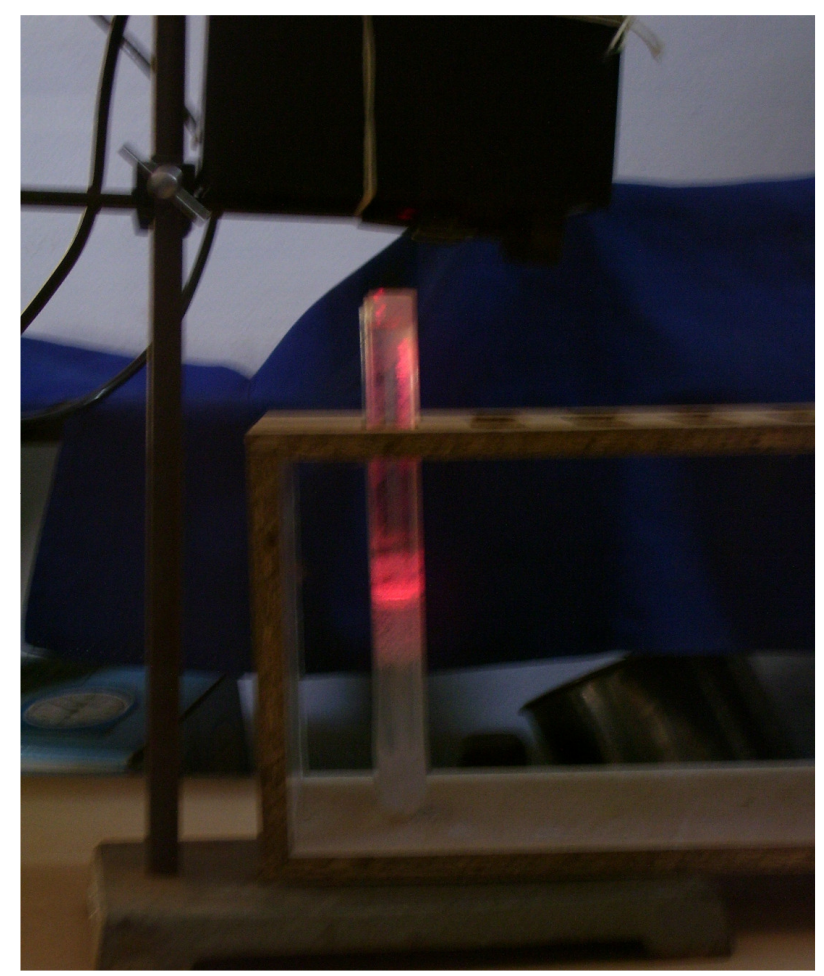

Fig-4. Growth of SrCrMHP crystal under laser exposed medium (SDP). 


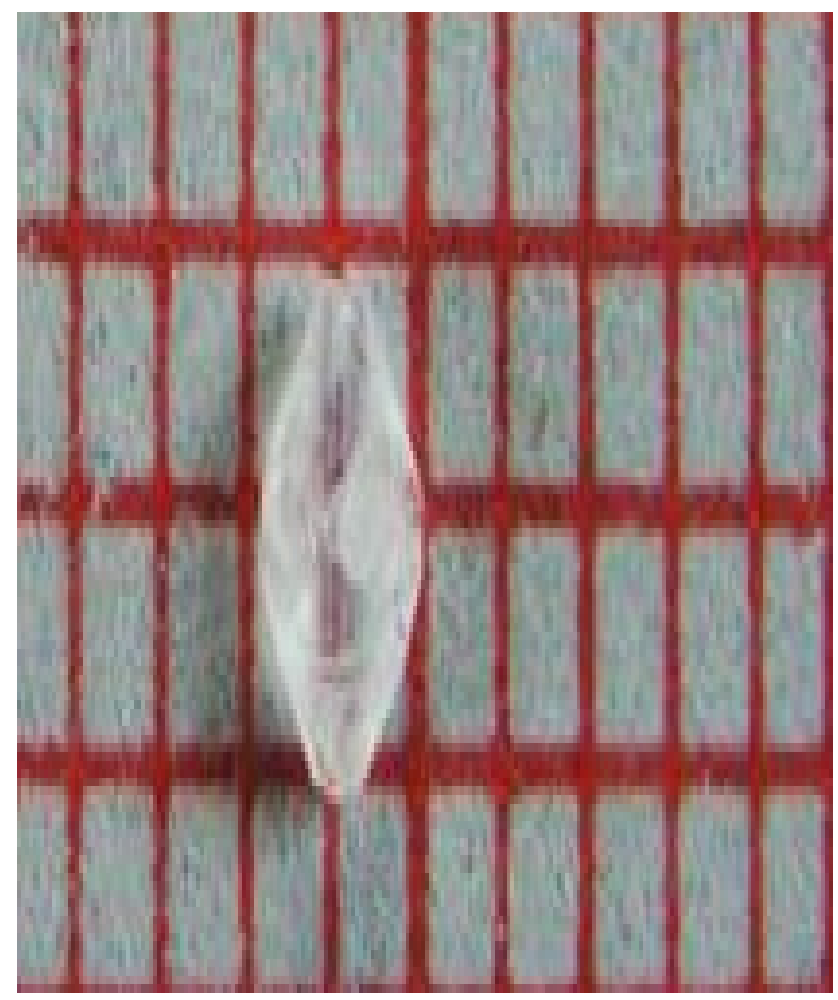

Fig-5. Harvested SrCrMHP crystals in SDP (3 mm x $3 \mathrm{~mm}$ x $3 \mathrm{~mm}$ ).

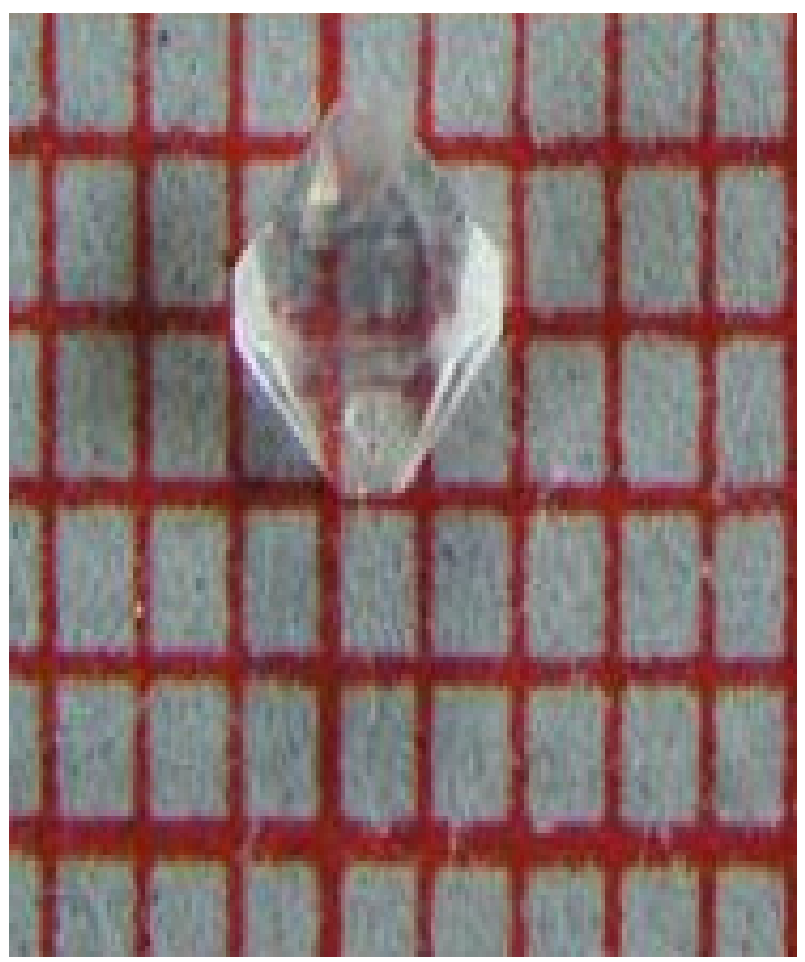

Fig-6. Harvested SrCrMHP crystals in DDP (3 mm x $3.5 \mathrm{~mm}$ x $3 \mathrm{~mm}$ ). 


\section{CHARACTERIZATION STUDIES of SrCrMHP CRYSTAL}

\subsection{FTIR Spectral Analysis of SrCrMHP Crystal}

FTIR spectrometer having $\mathrm{KBr}$ pellets sample holder and $\mathrm{KBr}$ detector was used for the analysis. The $\mathrm{KBr}$ pellet samples were used and the absorption frequencies range from 400 to $4000 \mathrm{~cm}^{-1}$. Fig-7 shows the FTIR spectrum of SrCrMHP crystal. The results matched with the reported values. The absorption bonds, absorption frequencies and percentage of transmittance were compared with the reported values. The values are tabulated in Table-3. The functional groups confirm the SrCrMHP crystal constituents [15-19].

\subsection{Thermo Gravimetric (TGA and DTA) Analysis of SrCrMHP Crystal}

The TGA and DTA of SrCrMHP crystal was carried out by STA 11500-PLTS instrument. SrCrMHP crystal sample of $1.290 \mathrm{mg}$ was taken for TGA process. The TGA was performed from room temperature to $1000^{\circ} \mathrm{C}$ by heating it at a constant rate. Fig. 8 shows the TGA and DTA graph of SrCrMHP crystal. The \% of weight of SrCrMHP sample present at a particular temperature is tabulated in Table-4 [20-24].

Strontium, chromium and magnesium are stable with respect to temperature up to $900{ }^{\circ} \mathrm{C}$. About $21.2 \%$ of SrCrMHP crystal sample was decomposed and $78.8 \%$ of the sample remains stable.

\subsection{Etching Study of SrCrMHP Crystal}

A well-grown $\mathrm{SrCrMHP}$ crystal was immersed in $\mathrm{HCl}$ solution at a desired concentration. The dissolution of SrCrMHP crystal depends upon the etchant concentration, temperature, and crystal morphology and etching time. The etch pits are shown in Fig-9. The etch pits observed in the photo are knife pits, cone pits, leaf pits and step pits [25-29]. 


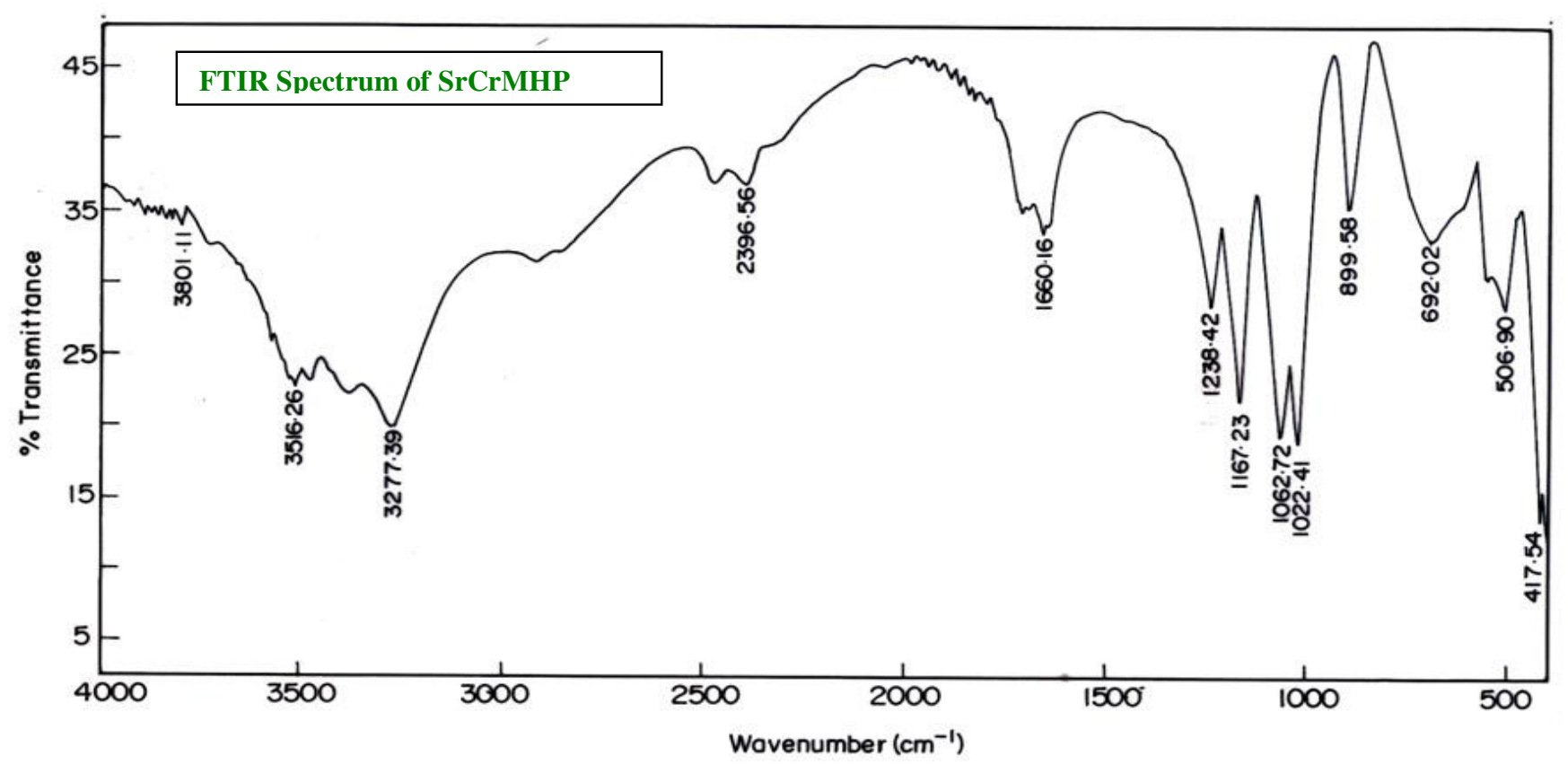

Fig-7. FTIR spectrum of SrCrMHP crystal. 
TABLE-3

FTIR spectral analysis of SrCrMHP crystal

\begin{tabular}{|c|c|c|c|c|}
\hline S.No. & Vibrations/Bonds & $\begin{array}{l}\text { Absorption } \\
\text { frequency } \\
\text { reported } \\
\text { values } \mathbf{c m}^{-1}\end{array}$ & $\begin{array}{l}\text { Absorption } \\
\text { frequency } \\
\text { observed } \\
\text { values cm-1 }\end{array}$ & $\begin{array}{c}\% \text { of } \\
\text { transmittance }\end{array}$ \\
\hline 1. & $\begin{array}{l}\mathrm{Sr}, \mathrm{Cr}, \mathrm{Mg} \& \text { hydrogen } \\
\text { O-H Symmetric, } \\
\text { asymmetric (in plane) }\end{array}$ & 3477 to 3047 & $\begin{array}{l}3277.39 \\
3516.26\end{array}$ & $\begin{array}{l}19.7 \\
22.5\end{array}$ \\
\hline 2. & $\begin{array}{l}\text { Out of plane } \mathrm{O}-\mathrm{H} \\
\text { bending }\end{array}$ & $662-780$ & 692.02 & 32.8 \\
\hline 3. & $\mathrm{PO}_{4}$ group & 1000 to 1100 & $\begin{array}{l}1167.26 \\
1062.72 \\
1022.41\end{array}$ & $\begin{array}{l}21.7 \\
19.1 \\
18.5\end{array}$ \\
\hline 4. & $\begin{array}{l}\mathrm{Sr}, \mathrm{Cr}, \text { magnesium/ } \\
\text { apatite groups }\end{array}$ & $\begin{array}{l}\text { 600-1010 (high } \\
\text { Frequency) }\end{array}$ & 692 & 32.8 \\
\hline 5. & $\begin{array}{c}\text { COD (Cr oxalate } \\
\text { dihydrate) }\end{array}$ & 517 & 506.90 & 28.1 \\
\hline
\end{tabular}




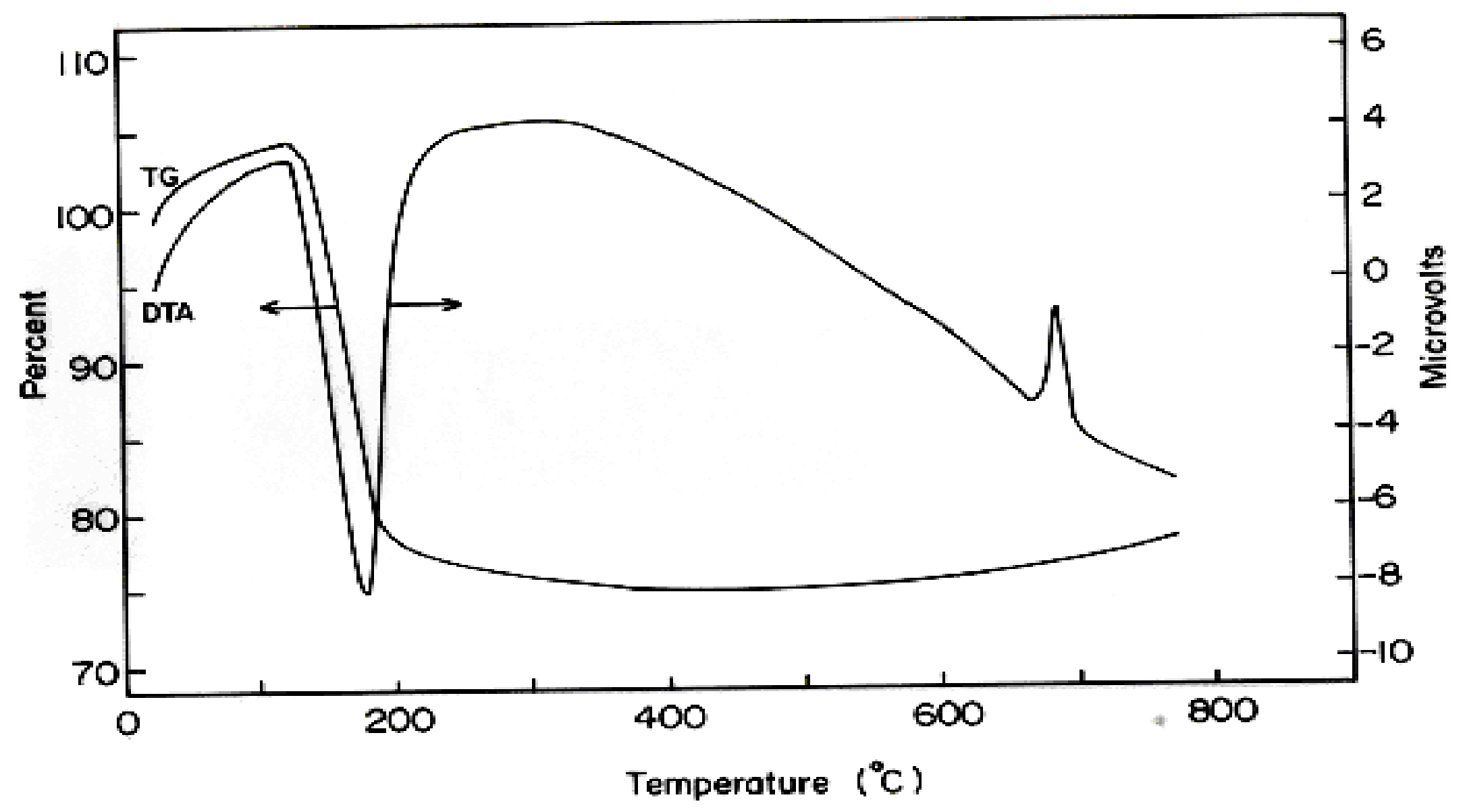

Fig-8. Thermo gravimetric (TGA and DTA) analysis of SrCrMHP crystal. 
TABLE- 4.

Thermal analysis of SrCrMHP crystal

\begin{tabular}{|c|c|c|c|c|}
\hline \multirow{2}{*}{ Points } & \multicolumn{3}{|c|}{ TGA } & \multirow{2}{*}{ DTA } \\
\cline { 2 - 4 } & \multirow{2}{*}{$\begin{array}{c}\text { Temperature } \\
\left({ }^{\circ} \mathrm{C}\right)\end{array}$} & $\begin{array}{c}\text { \% of SrCrMHP } \\
\text { crystal } \\
\text { present }\end{array}$ & $\begin{array}{c}\text { Quantity of } \\
\text { sample } \\
\text { remaining } \\
(\mathbf{m g})\end{array}$ & \multirow{2}{*}{ in ${ }^{0} \mathbf{C}$} \\
\hline & & & & \\
2 & 35 & 100 & 1.290 & 122.94 \\
3 & 122.19 & 104.4 & 1.35 & 170.33 \\
4 & 190.69 & 78.8 & 1.02 & 237.58 \\
5 & - & 78.8 & 1.02 & 668.33 \\
& - & 78.8 & 1.02 & 686.87 \\
\hline
\end{tabular}

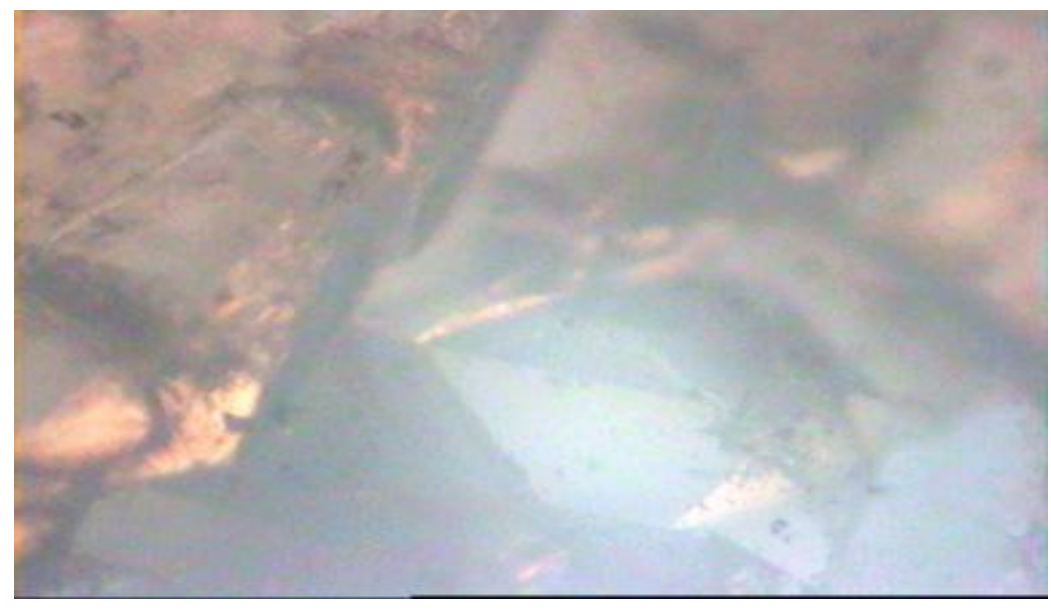

Fig-9. Chemical etching of SrCrMHP crystal at room temperature (1.5 mm - 40X).

\subsection{Scanning Electron Microscopic Study of SrCrMHP Crystal}

A well-grown SrCrMHP single crystal was selected for the investigation of surface morphology by using SEM. The SEM photograph was taken in the version S-300I instrument. The sample named VCA-600 was kept in lobe middle; the data size was 640 $\mathrm{x} 480 \mu \mathrm{m}$. The minor and major magnification of SEM was about 250 times. SEM accelerating voltage was 25000 volts and the sample was kept in a high vacuum at $18200 \mu \mathrm{m}$ working distance and monochromatic colour mode was employed. $50 \mu \mathrm{m}$ 
focusing of SrCrMHP crystal SEM is shown in Fig-10. In the surface analysis of SEMSrCrMHP crystal, smooth, fine grain boundaries and few valley regions were observed [30-38].

\subsection{X-ray Diffraction of SrCrMHP Crystal}

The single crystal XRD result reveals the crystalline nature of the grown crystal. The lattice parameters of the SrCrMHP crystal were calculated. The lattice index data are as follows.

CD0> LO

From to: 125

\begin{tabular}{|c|c|c|c|c|c|c|c|c|c|c|c|c|}
\hline $1 \mathrm{H}$ & 4. & -1 & 3. & * 11.18 & $S$ & -23.94 & 11.56 & -2.12 & $\star \star \mathrm{S}$ & 2 & 0.61 & 771.9 \\
\hline $2 \mathrm{H}$ & 4. & 1. & 3. & * 10.17 & S & -1.27 & 10.65 & -2.22 & $\star \star s$ & 2 & 0.52 & 691.4 \\
\hline $3 \mathrm{H}$ & 3. & 3. & 3. & * 10.30 & S & 20.47 & 8.00 & 6.41 & $\star * S$ & 2 & 0.55 & 8629.2 \\
\hline $4 \mathrm{H}$ & 2 . & 4. & 2 . & * 9.77 & S & 40.22 & 8.51 & 4.22 & $\star \star S$ & 2 & 0.63 & 32860.5 \\
\hline $5 \mathrm{H}$ & 3. & -2 . & 3. & 9.28 & S & -41.65 & 6.78 & 7.84 & $\star * \mathrm{~S}$ & 2 & 0.65 & 18929.0 \\
\hline $6 \mathrm{H}$ & 4. & 1. & 4. & * 11.37 & S & -6.17 & 9.08 & 8.04 & $\star * \mathrm{~S}$ & -2 & 0.60 & 2185.0 \\
\hline $7 \mathrm{H}$ & 4. & -1 . & 4. & * 11.39 & S & -26.55 & 8.96 & 8.33 & $\star \star S$ & -2 & 0.64 & 2317.0 \\
\hline $8 \mathrm{H}$ & 4. & -2 . & 4. & 11.89 & S & -35.60 & 9.03 & 8.10 & $\star * S$ & 2 & 0.68 & 20586.8 \\
\hline $9 \mathrm{H}$ & 1. & 1. & 5 . & 9.99 & S & -15.66 & -7.75 & 52.95 & $\star \star S$ & 2 & 0.66 & 479.8 \\
\hline $10 \mathrm{H}$ & -1 & 3. & 4. & * 9.99 & S & 29.11 & -11.67 & 62.97 & $\star * S$ & 2 & 0.89 & 15019.5 \\
\hline $11 \mathrm{H}$ & 0 . & 2 . & 5. & * 10.37 & S & 0.82 & -11.46 & 63.06 & $\star * S$ & 2 & 0.54 & 17371.0 \\
\hline $12 \mathrm{H}$ & 1 . & 0 . & 6. & * 11.69 & S & -32.48 & -7.62 & 57.31 & $\star \star S$ & 2 & 0.67 & 5865.0 \\
\hline $13 \mathrm{H}$ & 1 . & 2 . & 6. & * 12.36 & S & -5.31 & -5.73 & 53.01 & $* * \mathrm{~S}$ & 2 & 0.69 & 1626.3 \\
\hline $14 \mathrm{H}$ & -1 & 3. & 3. & * 8.53 & S & 41.39 & -10.73 & 56.32 & $\star \star \mathrm{S}$ & -2 & 0.68 & 1955.6 \\
\hline $15 \mathrm{H}$ & 1 . & 0 . & 4. & 7.90 & S & -30.41 & -8.75 & 50.74 & $\star \star x$ & -2 & 0.64 & 9272.4 \\
\hline $16 \mathrm{H}$ & 0 . & 2 . & 4. & 8.62 & S & 8.06 & -11.83 & 59.66 & $\star \star S \mathrm{~S}$ & -2 & 0.59 & 1588.7 \\
\hline $17 \mathrm{H}$ & 0 . & 0 . & 4. & 7.63 & S & -38.17 & -16.89 & 71.56 & $\star \star s$ & -2 & 0.65 & 2069.7 \\
\hline $18 \mathrm{H}$ & 0 . & 2 . & 6. & * 12.18 & S & -4.63 & -10.48 & 65.17 & $\star \star \mathrm{S}$ & -2 & 0.76 & 3917.2 \\
\hline $19 \mathrm{H}$ & -2 . & 4 . & 5. & * 13.17 & S & 36.66 & -9.78 & 66.59 & $\star * S$ & 2 & 0.67 & 9668.4 \\
\hline $20 \mathrm{H}$ & 0 . & 2 . & 7. & * 14.04 & S & -8.92 & -9.11 & 66.62 & $\star \star S$ & 2 & 0.68 & 14379.1 \\
\hline $21 \mathrm{H}$ & -1 & 3. & 4. & * 9.93 & S & 28.98 & -11.52 & 62.95 & $\star * \mathrm{~S}$ & 2 & 0.65 & 14779.0 \\
\hline $22 \mathrm{H}$ & 0 . & 2 . & 5. & * 10.38 & S & 0.66 & $-11 \cdot 32$ & 63.04 & $\star * S$ & 2 & 0.69 & 17581.7 \\
\hline $23 \mathrm{H}$ & 0 . & 2 . & 6. & * 12.18 & S & -4.82 & -10.34 & 65.17 & $\star * \mathrm{~S}$ & -2 & 0.78 & 4242.5 \\
\hline $24 \mathrm{H}$ & 1 . & 0 . & 6. & * 11.68 & S & -32.30 & -7.67 & 57.26 & $* * S$ & 2 & 0.76 & 5968.1 \\
\hline $25 \mathrm{H}$ & 1 . & 2 . & 6 . & * 12.35 & S & -5.37 & -5.66 & 53.00 & $\star \star S$ & 2 & 0.93 & 16833.1 \\
\hline
\end{tabular}

\begin{tabular}{|c|c|c|c|c|c|c|}
\hline $\begin{array}{lcr}\mathrm{Nr} & \mathrm{S} & \mathrm{H} \\
0.0093629\end{array}$ & K & L & Dev-Ang & dTh & $\mathrm{dPh}$ & $\mathrm{dCh}$ \\
\hline $\begin{array}{l}1 \mathrm{H} \quad 4.009 \\
0.0010538\end{array}$ & -1.002 & 2.995 & 0.1061 & -0.011 & 0.019 & 0.105 \\
\hline $\begin{array}{cc}2 \mathrm{H} & 3.999 \\
0.0002487\end{array}$ & 1.000 & 3.003 & 0.0266 & -0.002 & 0.001 & -0.027 \\
\hline $\begin{array}{c}3 \mathrm{H} \\
0.0003242 \\
0.0097\end{array}$ & 2.999 & 3.002 & 0.0338 & 0.003 & -0.003 & -0.034 \\
\hline $\begin{array}{c}4 \mathrm{H} \\
0.0003231\end{array}$ & 4.002 & 2.003 & 0.0273 & -0.005 & -0.005 & -0.027 \\
\hline $\begin{array}{c}5 \mathrm{H} \quad 3.000 \\
0.0004269\end{array}$ & -2.001 & 3.004 & 0.0365 & -0.006 & -0.006 & -0.036 \\
\hline $\begin{array}{c}6 \mathrm{H} \quad 3.998 \\
0.0004750\end{array}$ & 0.999 & 3.995 & 0.0228 & 0.009 & 0.000 & 0.023 \\
\hline $\begin{array}{cc}7 \mathrm{H} & 3.998 \\
0.0002439\end{array}$ & -0.998 & 4.000 & 0.0158 & 0.004 & -0.012 & -0.010 \\
\hline $\begin{array}{c}8 \mathrm{H} \quad 3.998 \\
0.0002931\end{array}$ & -1.998 & 4.000 & 0.0226 & 0.004 & -0.014 & -0.018 \\
\hline
\end{tabular}




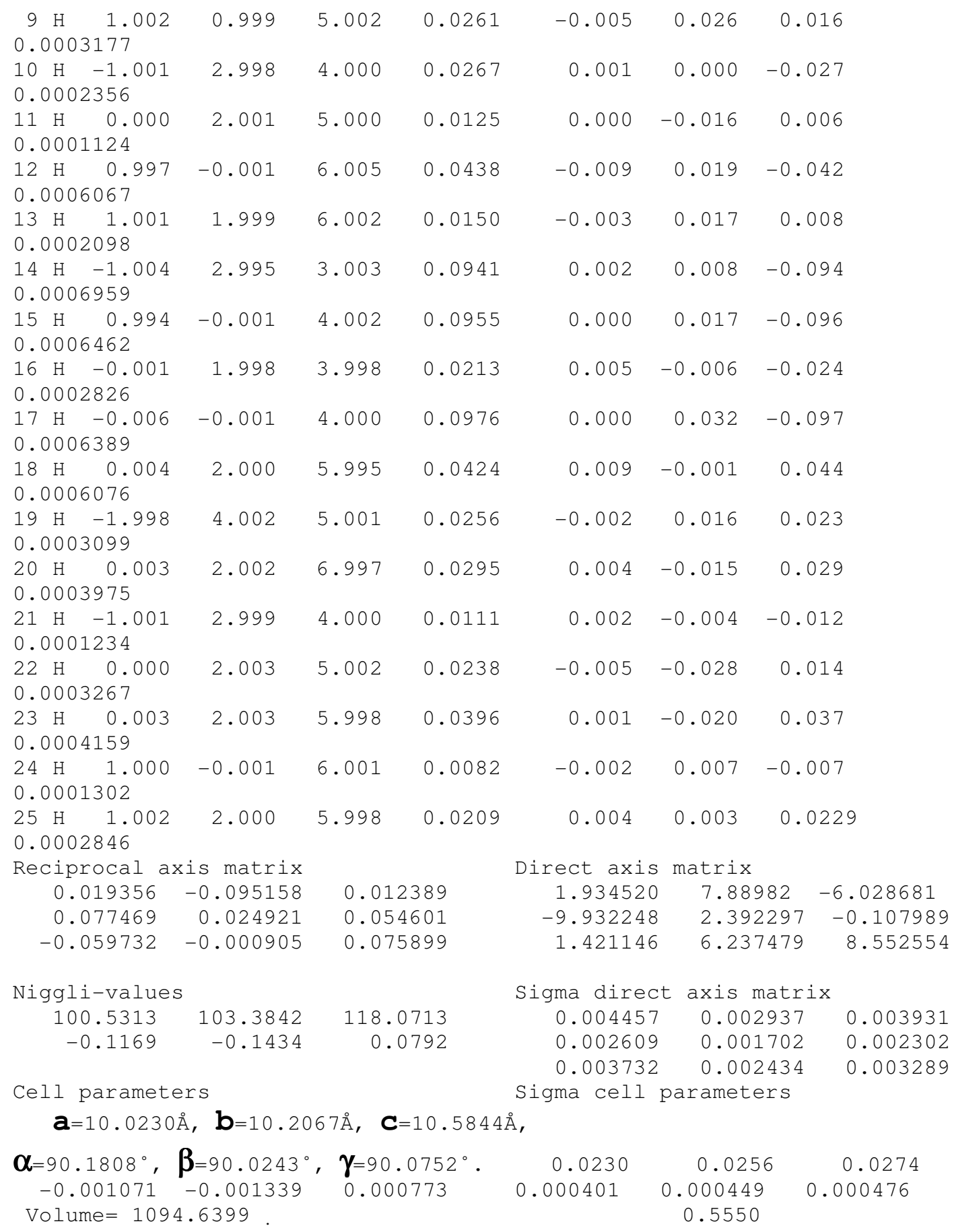

Index-Status: HHHHнHнHнHнHнHнHнHнHнHнHн

CDO>

The lattice parameters are $\mathbf{a}=10.0230 \AA, \quad \mathbf{b}=10.2067 \AA, \quad \mathbf{c}=10.5844 \AA, \quad \alpha=90.1808^{\circ}$, $\beta=90.0243^{\circ}$ and $\gamma=90.0752^{\circ}$. The volume of the unit cell of the SrCMHP crystal is $1094.6399(\AA)^{3}$. From this data, it is confirmed that the SrCMHP crystal system is triclinic. 


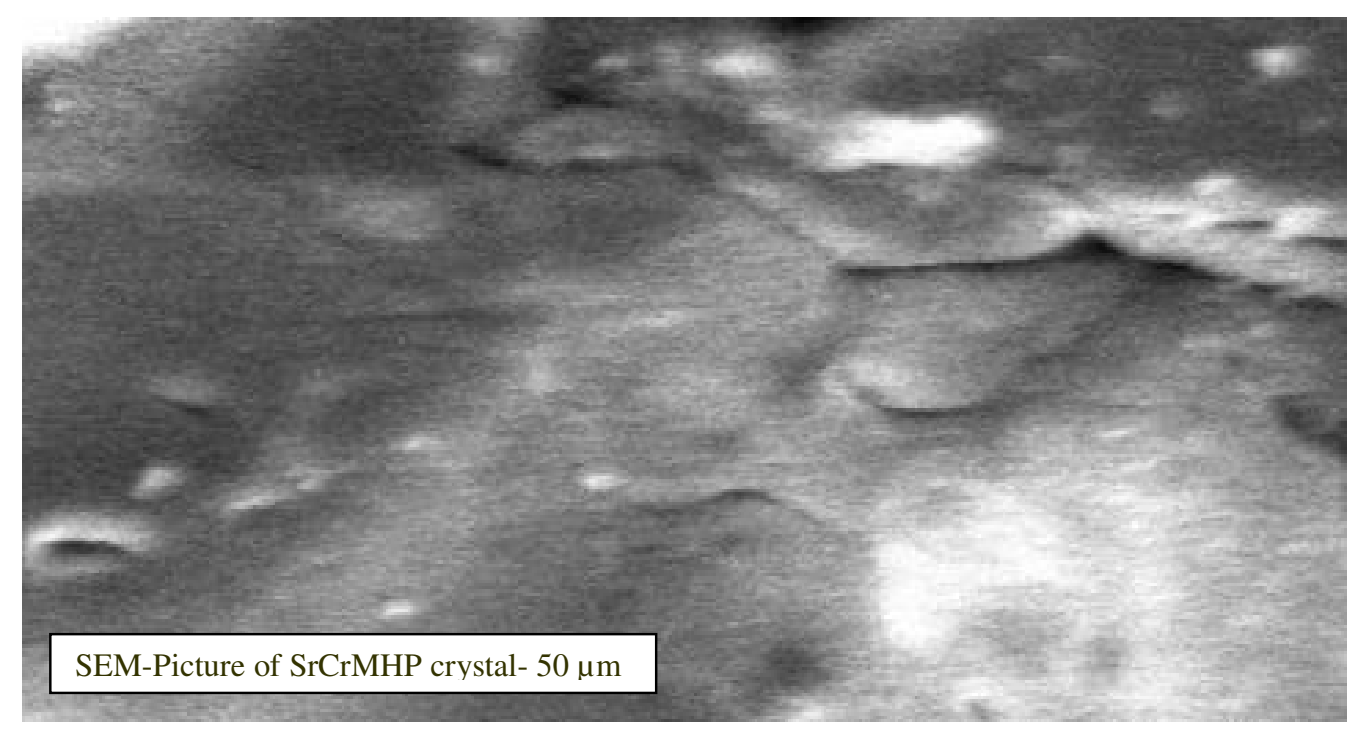

Fig-10. SEM picture of SrCrMHP crystal.

\section{CONCLUSION}

The crystal structures, growth morphology, chemical constituents, surface morphology and TGA/DTA analysis of Strontium chromium magnesium hydrogen phosphate (SrCrMHP) crystals have been investigated. The SrCrMHP crystals were grown under three different growth conditions. The optimum growth environments have been identified. FTIR spectrum was recorded and the functional group analysis of SrCrMHP crystal confirms the SrCrMHP chemical constituents. Chemical etching studies were carried out at room temperature and the etch pits are identified. The surface morphology of the grown crystal was recorded using SEM photograph. The thermal stabilities of the crystal were investigated by TGA/DTA analysis. XRD data confirm that the SrCrMHP crystals belong to triclinic system.

\section{REFERENCES}

[1] C.Y.C. Pak, et al, Effects of de-posphonate on crystallization of calcium oxalate in-vitro, Kidney.Int.7 (1975) 154-160.

[2] L.Goe, Manual of Nephrology in the patients with renal stone, W. Sckrier (4 ${ }^{\text {th }}$ edi..) Little Brous, (1981).

[3] P. Sundaramoorthi, S.Kalainathan, Growth of $\mathrm{CaHPO}_{4}$ crystals in silica gel media and its characterization studies, nucleation reduction process. Asian journal of chemistry, 19 (2007) (In press)

[4] M.Menon, Compbell's Urology-3, New York, (1998). 
[5] S.Joshi and J.Joshi, FTIR spectroscopic, thermal and growth morphological studies of calcium hydrogen phosphate dehydrate crystals, Cryst.Res.Technol.38, (2003) 817-821.

[6]. P.Sundaramoorthi, S.Kalainathan, Growth and characterizations studies of SMHP single crystal in silica gel medium and laser induced nucleation reduction process. Biochemical Engineering Journal, 34 (2007) 244-249.

[7] P.Sundaramoorthi, S. Kalainathan, Characteristics studies of SHP crystals are grown in silica gel medium. Asian journal of chemistry, 19 (5) (2007) 3739-3746

[8] P.Sundaramoorthi, S.Kalainathan, Crystal growth of some renal stones constituents: I In vitro crystallization of trace element and its characterization studies. The Journal of minerals and materials characterization of Engineering (In press)

[9] P.Sundaramoorthi, S.Kalainathan, BMHP single crystal growth in silica gel medium, characterization studies and laser irradiated nucleation reduction process strategy. Asian journal of chemistry, 19 (2007) (In press)

[10] J. Dennis, Crystal growths in gels, J.Elec.Che.Soc.14 (1967) 263.

[11] J.W. Mullin, Crystallization, Butter worth scientific pub. London 4, (1961).

[12] E. Hatscheck, Light affects the crystallization nuclei. Kollid Z.37 (1925) 297.

[13] A.J Arminstrong, The scraped sell crystallizer, British chemical engineering, 14 (1969) 647-649.

[14] H.K. Henisch, J.I. Hanoka, and J. Dennis, Surface barrier effects of crystals growth in gel medium, J.Electrochem.Soc.112 (1965) 627.

[15] G. Socrater, Infrared Cha. Group Friq, Johnwilly, Chichester, (1980).

[16] S. Matsuzaki, K. Matsushita, K. Tanykawa, A. Masuda and F. Matsunaga, Sequential analysis of recurrent calcium calculi by infrared spectroscopy, Int.J.Uro.2 (1995) 235-237.

[17] Yean-Chin Tsay, Application of infrared spectroscopy to analysis of urinary calculi, J.Urol. 86 (1961) 838-854.

[18] C.M. Corns, Infrared analysis of renal calculi-a comparison with conventional technique. J.Ann. Clin. Bio-Cherm 20 (1983) 20-35.

[19] A. Hesse and D. Bach, Stone analysis by infrared spectroscopy, In., Urinary stones, Clinical and laboratory Aspects, Edi., Alan Rose, University Park Press, Baltimore, (1982).

[20] P.N. Kotru, K.K. Raina and N.K Guptha, Characterizations as thermal behavior of Lanthanum tartar ate crystals grown from gels. Bull. Mater Sci.8 (1986) 547.

[21] Anand Kumar Sharma, Shyam Kumar and Narender Kumar Kaushik, Thermal Studies on magnesium, barium and lead, zirconyloxalates, Thermochimica Acta, 47(1981) 149-156.

[22] G. Bruzzone, The binary systems calcium-copper, strontium-copper and bariumcopper, J. Less Common Metals, 25 (1971) 361-366.

[23] G. Bruzzone, The binary systems Sr-In and Ba-In.J. Less Common Metals, 11, (1966) 249-258. 
[24] Sedat Ilhan, Cem Kahruman and Ibrahim Yusufoglu, Characterization of the thermal decomposition products of ammonium phosphomolybdate hydrate, J. Analytical and Applied Pyrolysis, 78 (2007) 363-370.

[25] J.J. Gilman, J. Johnsion and G.W. Sears, Dislocation etch pit formation in Lithium fluoride, J.App. Physics, 295 (1958) 749.

[26] J.J. Gilman, et al, Observations Lithium fluoride dislocation glide climb in Lithium fluoride crystals, J.App. Physics, 27 (1956) 1018.

[27] J.C. Fisher, In: Dissolutions and Mechanical Properties of Crystals, John Wiley and sons, New York, (1957).

[28] J.B. New Kirk, In: Director Observation of Imperfection in crystals, Inter science Publishers, New York (1962).

[29] K. Sangwal, Chemical etching principles and the present status, Key Engineering Materials, 58 (1991) 170-187.

[30] K. Tasukamot, In situ observation of mono-molecular growth step on crystal growth in aqueous solution-I, J. Cry. Growth, 61 (1983) 199.

[31] H.C. Gates, Thirty years of progress in Surface Science, In: Crystal growth and characterization, Edi, North Holland, (1975).

[32] H. Bethage, et al, edi, Electron Microscopy in Solid State Physics, Elsever, Amsterdom, (1987).

[33] N. Albon et al, In: Growth and Perfection of Crystals, Wiley., New York, (1958).

[34] H.K. Henisch, J.M. Garcia-Ruiz, Crystal growth in gels and Lisegang ring formation, J.Crystal Growth, 75 (1986) 195.

[35] H.K. Henisch, J.M. Garcia-Ruiz, Crystal growth in gels and Lisegang ring formation-II crystallization criteria and successive precipitation, J.Cry.Growth 75 (1986) 203.

[36] H.K. Henisch, Crystals in Gel and Liesegang Rings, Cambridge University press, Cambridge (1986). 